\title{
The impact of stage of labor on adverse maternal and neonatal outcomes in multiparous women: a retrospective cohort study
}

Li Wang ${ }^{1,2}$, Hongxia Wang ${ }^{3}$, Lu Jia ${ }^{1}$, Wenjie Qing ${ }^{2,4}$, Fan Li ${ }^{2,5}$ and Jie Zhou ${ }^{2 *}$

\begin{abstract}
Background: The correlation between stage of labor and adverse delivery outcomes has been widely studied. Most of studies focused on nulliparous women, it was not very clear what impact the stage of labor duration had on multiparous women.

Methods: A retrospective cohort study was conducted among all the multiparous women of cephalic, term, singleton births, who planned vaginal delivery. The total stage of labor covered the first stage and the second stage in this study, and they were divided into subgroups. Adverse maternal outcomes were defined as referral cesarean delivery, instrumental delivery, postpartum hemorrhage, perineal laceration (III and IV degree), hospitalization stay $\geq 90$ th, and adverse neonatal outcomes as NICU, shoulder dystocia, Apgar score $\leq 7(5 \mathrm{~min})$, neonatal resuscitation, assisted ventilation required immediately after delivery.

Results: There were 7109 parturients included in this study. The duration of first stage was 6.2(3.6-10.0) hours, the second stage was 0.3(0.2-0.7) hour, the total stage was 6.9(4.1-10.7) hours in multiparous women. At the first stage, the rates of overall adverse outcome were $21,23.4,28.8,35.5,38.4 \%$ in subgroups $<6 \mathrm{~h}, 6-11.9 \mathrm{~h}, 12-17.9 \mathrm{~h}, 18-23.9 \mathrm{~h}$, $\geq 24 \mathrm{~h}$, which increased significantly $\left(X^{2}=57.64, P<0.001\right)$, and ARR $(95 \% \mathrm{Cl})$ were $1.10(0.92,1.31), 1.33(1.04,1.70), 1.80(1.21,2.68), 2.57$ $(1.60,4.15)$ compared with subgroup $<6 \mathrm{~h}(\mathrm{ARR}=1)$; At the second stage, the rates of overall adverse outcome were 20.0, $30.7,38.5,61.2,69.6 \%$ in subgroups $<1 \mathrm{~h}, 1-1.9 \mathrm{~h}, 2-2.9 \mathrm{~h}, 3-3.9 \mathrm{~h}, \geq 4 \mathrm{~h}\left(\mathrm{X}^{2}=349.70, P<0.001\right)$, and ARR $(95 \% \mathrm{Cl})$ were 1.89 $(1.50,2.39), 2.22(1.55,3.18), 10.64(6.09,18.59), 11.75(6.55,21.08)$ compared with subgroup $<1 \mathrm{~h}(\mathrm{ARR}=1))$. At the total stage, the rates of overall adverse outcome were $21.5,30.8,42.4 \%$ in subgroups $<12 \mathrm{~h}, 12-23.9 \mathrm{~h}, \geq 24 \mathrm{~h}\left(\mathrm{X}^{2}=84.90, P<\right.$ 0.001), and ARR (95\% Cl) were 1.41 (1.16,1.72), $3.17(2.10,4.80)$ compared with subgroup < $12 \mathrm{~h}(\mathrm{ARR}=1)$.
\end{abstract}

Conclusions: The prolonged stage of labor may lead to increased adverse outcomes in multiparous women, it was an independent risk factor of adverse maternal and neonatal outcomes.

Keywords: First stage of labor, Second stage of labor, Maternal outcomes, Neonatal outcomes, Adverse outcomes, Multiparous women

\footnotetext{
* Correspondence: 876685235@qq.com

${ }^{2}$ Department of Anesthesiology, Perioperative and Pain Medicine, Brigham and Women's Hospital, Harvard Medical School, 75 Francis St, Boston, MA 02115, USA

Full list of author information is available at the end of the article
}

(c) The Author(s). 2020 Open Access This article is licensed under a Creative Commons Attribution 4.0 International License, which permits use, sharing, adaptation, distribution and reproduction in any medium or format, as long as you give appropriate credit to the original author(s) and the source, provide a link to the Creative Commons licence, and indicate if changes were made. The images or other third party material in this article are included in the article's Creative Commons licence, unless indicated otherwise in a credit line to the material. If material is not included in the article's Creative Commons licence and your intended use is not permitted by statutory regulation or exceeds the permitted use, you will need to obtain permission directly from the copyright holder. To view a copy of this licence, visit http://creativecommons.org/licenses/by/4.0/. The Creative Commons Public Domain Dedication waiver (http://creativecommons.org/publicdomain/zero/1.0/) applies to the data made available in this article, unless otherwise stated in a credit line to the data. 


\section{Background}

In 2014, in order to reduce the rate of cesarean delivery, the guideline of Safe Prevention of the Primary Cesarean Delivery was recommended by American College of Obstetricians and Gynecologists (ACOG) [1]. The guideline indicated that the prolonged stage of labor may reduce the rate of primary cesarean delivery, and no absolute maximum duration of first and second stage of labor was defined, which was different from Friedman's Chart [2]. After that, the correlation between stage of labor and adverse delivery outcomes has been widely studied. Most of studies focused on nulliparous women. Some researches supported the original contention that the prolonged second stage beyond historical precepts was unsafe [3, 4]; The implementation of the guideline could not reduce the rate of cesarean delivery, but increased the adverse outcomes of mothers and neonates on the contrary [5], or reduced the rate of primary cesarean delivery successfully, but increased other immediate maternal and neonatal complications [6]; The prolonged first or second stage of labor was related to adverse outcomes [6-9].

It was known that the stage of labor of multiparous women was shorter than that of nulliparous women [10], but it was not very clear what impact the duration of first stage and second stage of labor had on delivery outcomes in multiparous women. We assumed that the prolonged stage of labor might also lead to increased adverse outcomes. In this study, we aimed to evaluate the impact of the duration of stage of labor on delivery outcomes in multiparous women, to further understand the process of labor.

\section{Methods}

This is a retrospective cohort study, the data was collected from the electronic medical records from January 1, 2016 to December 31, 2018 in Harvard University Partners Healthcare Systems (PARTNERS), covering seven hospitals: Brigham and Women's Hospital, Massachusetts General Hospital, Newton-Wellesley Hospital, North Shore Medical Center, Martha's Vineyard Hospital, Cooly Dickinson Hospital and Nantucket Cottage Hospital. The collected information of demographics and obstetrics characteristics included gestational age, maternal age, maternal height, weight gain, BMI, gravidity, parity, baby weight, baby height, ethnicity, epidural analgesia, induction, oxytocin, etc., the adverse maternal outcomes included referral cesarean delivery, instrumental delivery, postpartum hemorrhage, III and IV degree laceration, length of stay $\geq 90$ th (hospitalization stay $\geq 90$ th), and the adverse neonatal outcomes included NICU, shoulder dystocia, Apgar score $\leq 7 \quad(5$ min), neonatal resuscitation, assisted ventilation required immediately after delivery.

The inclusion criteria was multiparous women (parity $\geq 1$ ), with singleton gestation, $37-41^{+6}$ gestational weeks, cephalic presentation (excluding face and brow), vaginal delivery, unexpected cesarean delivery during the first or second stage of labor. The exclusion criteria was scheduled cesarean delivery, previous cesarean delivery history, stillbirth, pregnancy induced hypertension, gestational diabetes, and missing data of the duration of first or second stage of labor, or other data. A flow chart was showed in Fig. 1. The first stage of labor was defined as the phase from regular uterine contractions to full cervical dilation. If the cervix had been dilated at the time of admission, the admission time was the beginning of first stage. The second stage was defined as the phase from full cervical dilation to delivery of fetus. The duration of first stage of labor was divided into five subgroups as $<6 \mathrm{~h}, 6-11.9 \mathrm{~h}$, $12-17.9 \mathrm{~h}, 18-23.9 \mathrm{~h}, \geq 24 \mathrm{~h}$. The duration of second stage of labor was divided into five subgroups as $<1 \mathrm{~h}, 1-1.9 \mathrm{~h}$, $2-2.9 \mathrm{~h}, 3-3.9 \mathrm{~h}, \geq 4 \mathrm{~h}$. The total stage of labor covered the first stage and the second stage, it was divided into three subgroups as $<12 \mathrm{~h}, 12-23.9 \mathrm{~h}, \geq 24 \mathrm{~h}$.

Data description was presented as mean \pm standard deviation (Mean $\pm \mathrm{SD}$ ) or median (interquartile ranges, IQR) for continuous variables and percentages for categorical variables. Linear trend $X^{2}$ analysis was used for categorical variables as group comparison. The duration of stage of labor were defined as independent variables. The adverse outcomes were defined as dependent variables. Multivariable logistic regression model was used to assess the correlation between the duration of stage of labor and adverse delivery outcomes. Adjusted Risk Ratio (ARR) and 95\% Confidence Interval (CI) were used to expressed the association in multivariable logistic models with the shortest duration of the stage of labor ( $<6 \mathrm{~h}$ of the first stage $<1 \mathrm{~h}$ of the second stage $<12 \mathrm{~h}$ of the total stage) as reference, after adjusting the factors such as gestational age, maternal age, maternal height, weight gain, BMI, gravidity, parity, baby weight, epidural analgesia, induction, oxytocin. All statistical tests of hypotheses will be two sided and criterion for statistical significance is $\alpha=0.05$. Statistical analyses were done with SPSS version 21.0 software (IBM).

\section{Results}

There were 43,577 deliveries in Harvard University Partners Healthcare Systems (PARTNERS) from January 1, 2016 to December 31, 2018, including 29,943 vaginal deliveries and 13,634 cesarean deliveries, the rate of cesarean delivery was $31.3 \%$. There were 7109 multiparous women who planned for vaginal delivery and encountered the labor process, $76.3 \%$ with epidural analgesia, $27.8 \%$ with oxytocin (Table 1). The duration of first stage was 6.2(3.6-10.0) hours in multiparous women, the second stage was $0.3(0.2-0.7)$ hours, the total stage was $6.9(4.1-$ 10.7) hours. The rate of overall adverse outcomes was $23.6 \%$, the rate of maternal adverse outcomes was $9.4 \%$, 


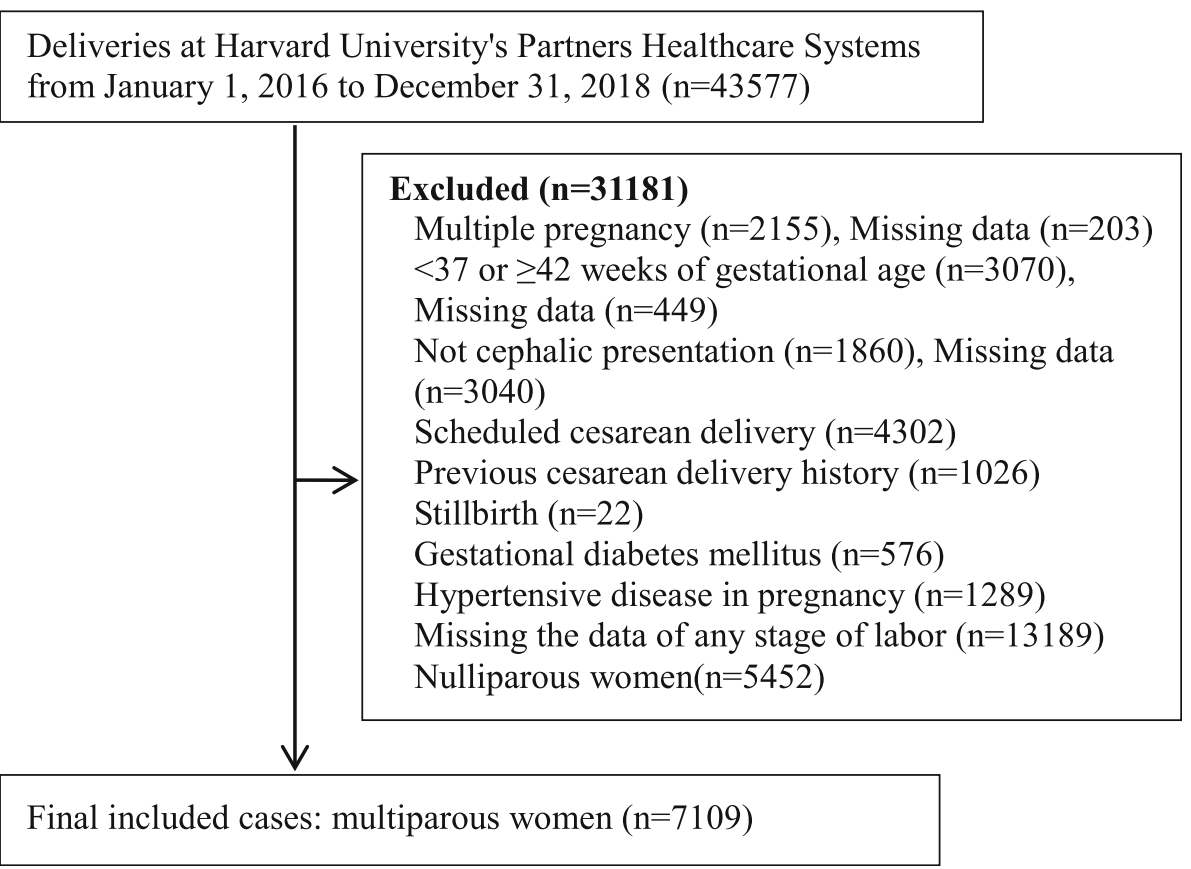

Fig. 1 The flow chart

the rate of neonatal adverse outcomes was $17.1 \%$, other adverse outcomes were showed in Table 2 .

With the prolongation of first stage, the rates of overall adverse outcomes were $21,23.4,28.8,35.5,38.4 \%$ in subgroups $<6 \mathrm{~h}, 6-11.9 \mathrm{~h}, 12-17.9 \mathrm{~h}, 18-23.9 \mathrm{~h}, \geq 24 \mathrm{~h}$, the rates increased significantly $\left(X^{2}=57.64, P<0.001\right)$. The rate of maternal adverse outcomes was 7.2, 8.8, 13.8, 20.2, $29.8 \%$ respectively, which increased significantly $\left(X^{2}=\right.$ 121.38, $P<0.001)$; The rate of neonatal adverse outcomes was $16.0,17.3,19.3,21.5,18.5 \%$ respectively, which increased significantly $\left(X^{2}=7.75, P=0.005\right)$. There were significant differences in the incidence of referral cesarean delivery, instrumental delivery, length of stay $\geq 90$ th, shoulder dystocia, Apgar $\leq 7(5 \mathrm{~min})$, neonatal resuscitation, assisted ventilation in different duration of the first stage (Table 3, Fig. 2). In order to assess the effect of duration of labor on adverse outcomes, we made the following analysis, with $<6 \mathrm{~h}$ as the reference. Multivariable logistic regression showed that ARR $(95 \% \mathrm{CI})$ of overall adverse outcomes were $1.10(0.92,1.31), 1.33(1.04,1.70), 1.80(1.21,2.68), 2.57(1.60$, 4.15 ) in subgroups of $6-11.9 \mathrm{~h}, 12-17.9 \mathrm{~h}, 18-23.9 \mathrm{~h}, \geq 24$ $\mathrm{h} ; \operatorname{ARR}(95 \% \mathrm{CI})$ of maternal adverse outcomes were $1.31(1.01,1.71), 2.42(1.74,3.37), 3.15(1.92,5.18), 5.52(3.19$, 9.58); $\operatorname{ARR}(95 \% \mathrm{CI})$ of neonatal adverse outcomes were $1.04(0.85,1.26), 0.95(0.71,1.27), 1.28(0.81,2.02), 1.27(0.71$, 2.25). The risk of referral cesarean delivery and length of stay $\geq 90$ th increased with prolonged first stage. This was showed in Additional file 1: Table S1, Fig. 3. In order to understand the impact of different cutoff values on the risk of overall adverse outcomes, the first stage $<6 \mathrm{~h}$ and $\geq 6 \mathrm{~h}$ were compared, $\operatorname{ARR}(95 \% \mathrm{CI})$ was $1.23(1.05,1.43)$; if the cutoff values were $12 \mathrm{~h}, 18 \mathrm{~h}, 24 \mathrm{~h}, \mathrm{ARR}(95 \% \mathrm{CI})$ were $1.48(1.22,1.80), 1.92(1.41,2.59), 2.33(1.45,3.72)$; ARR(95\% CI) of maternal adverse outcomes were $1.76(1.40,2.22)$, $2.55(1.98,3.28), 3.61(2.13,4.40), 4.05(2.39,6.86)$, ARR $(95 \%$ CI) of neonatal adverse outcomes were $1.04(0.87,1.24)$, $1.03(0.82,1.30), 1.26(0.88,1.81), 1.25(0.71,2.19)$ with $6 \mathrm{~h}, 12$ $\mathrm{h}, 18 \mathrm{~h}, 24 \mathrm{~h}$ as cutoff values. The risk of referral cesarean delivery and length of stay $\geq 90$ th increased with the change of cutoff values. Other outcomes were showed in Additional file 2: Table S2, Fig. 3.

With the prolongation of second stage of labor, the rates of overall adverse outcomes were 20.0, 30.7, 38.5, 61.2, $69.6 \%$ in subgroups $<1 \mathrm{~h}, 1-1.9 \mathrm{~h}, 2-2.9 \mathrm{~h}, 3-3.9 \mathrm{~h}, \geq 4 \mathrm{~h}$ $\left(X^{2}=349.70, P<0.001\right)$. The rate of maternal adverse outcomes increased from $5.9,14.6,25.2,45.0$, to $64.4 \%\left(X^{2}=\right.$ 821.97, $P<0.001)$; The rate of neonatal adverse outcomes was $16.0,19.6,21.2,31.8,27.4 \%$, which increased significantly $\left(X^{2}=38.06, P<0.001\right)$. There were significant differences in the rate of referral cesarean delivery, instrumental delivery, postpartum hemorrhage, III and IV degree laceration, length of stay $\geq 90$ th, NICU, Apgar $\leq 7(5 \mathrm{~min})$, neonatal resuscitation, assisted ventilation in second stage of labor (Table 4, Fig. 4). With $<1 \mathrm{~h}$ as the reference group of second stage, ARR $(95 \% \mathrm{CI})$ of $1-1.9 \mathrm{~h}, 2-2.9 \mathrm{~h}, 3-3.9 \mathrm{~h}, 4 \mathrm{~h}$ were $1.89(1.50,2.39), 2.22(1.55,3.18), 10.64(6.09,18.59)$, $11.75(6.55,21.08)$ in overall adverse outcomes; ARR $(95 \% \mathrm{CI})$ were $2.51(1.83,3.44), 4.69(3.09,7.12), 13.87(8.21,23.44)$, 28.63 ( $16.26,50.40)$ in maternal outcomes; $\operatorname{ARR}(95 \% \mathrm{CI})$ were 1.46 (1.12,1.91), $1.28(0.83,1.98), 3.89(2.33,6.49), 1.68(0.91,3.10)$ in 
Table 1 Demographics and obstetrics characteristics of multiparous women $(n=7109)$

\begin{tabular}{|c|c|c|}
\hline & Median/n & IQR/\% \\
\hline \multicolumn{3}{|l|}{ Duration of stage of labor } \\
\hline First stage (hour) $^{a}$ & 6.2 & $3.6-10.0$ \\
\hline$<6 h$ & 3398 & 47.8 \\
\hline $6-11.9 h$ & 2512 & 35.3 \\
\hline $12-17.9 \mathrm{~h}$ & 820 & 11.5 \\
\hline 18-23.9h & 228 & 3.2 \\
\hline$\geq 24 \mathrm{~h}$ & 151 & 2.1 \\
\hline Second stage (hour) a & 0.3 & $0.2-0.7$ \\
\hline$<1 \mathrm{~h}$ & 5791 & 81.5 \\
\hline $1-1.9 \mathrm{~h}$ & 776 & 10.9 \\
\hline $2-2.9 \mathrm{~h}$ & 278 & 3.9 \\
\hline $3-3.9 h$ & 129 & 1.8 \\
\hline$\geq 4 h$ & 135 & 1.9 \\
\hline Total stage (hour) $^{a}$ & 6.9 & $4.1-10.7$ \\
\hline$<12 \mathrm{~h}$ & 5717 & 80.4 \\
\hline $12-23.9 \mathrm{~h}$ & 1208 & 17.0 \\
\hline$\geq 24 \mathrm{~h}$ & 184 & 2.6 \\
\hline Gestational age (weeks) ${ }^{a}$ & 39.6 & $39.0-40.3$ \\
\hline Maternal age (years) ${ }^{a}$ & 33.0 & $30.0-36.0$ \\
\hline Maternal Height $(\mathrm{cm})^{a}$ & 162.6 & $160.0-167.6$ \\
\hline Gestational weight gain $(\mathrm{kg})^{\text {a }}$ & 14.0 & $10.0-17.0$ \\
\hline Maternal BMI $\left(\mathrm{kg} / \mathrm{m}^{2}\right)^{\mathrm{a}}$ & 29.4 & $26.6-32.6$ \\
\hline Gravidity $^{a}$ & 3.0 & $2.0-4.0$ \\
\hline Parity $^{\mathrm{a}}$ & 2.0 & $2.0-3.0$ \\
\hline Baby weight (g) ${ }^{a}$ & 3459 & $3175-3750$ \\
\hline Baby height $(\mathrm{cm})^{a}$ & 50.8 & $48.3-52.1$ \\
\hline \multicolumn{3}{|l|}{ Ethnicity } \\
\hline Non-Hispanic White & 4671 & 65.7 \\
\hline Non-Hispanic Black & 558 & 7.9 \\
\hline Hispanic & 273 & 3.8 \\
\hline Asian or Pacific Islanders & 737 & 10.4 \\
\hline Other or Unknown & 870 & 12.2 \\
\hline Epidural analgesia & 5423 & 76.3 \\
\hline Induction & 1647 & 23.2 \\
\hline Oxytocin & 1975 & 27.8 \\
\hline
\end{tabular}

Data was presented as $\mathrm{n}(\%)$ or ${ }^{\mathrm{a}}$ median (interquartile range, non-normal distribution)

neonatal outcomes; other outcomes showed in Additional file 3: Table S3, Fig. 5. Regarding the impact of cutoff values of second stage on the risk of adverse outcomes, ARR (95\% CI) of overall adverse outcomes were $2.71(2.25,3.26)$, $4.08(3.15,5.28), 9.51(6.33,14.28), 9.31(5.20,16.65)$ with $1 \mathrm{~h}$, $2 \mathrm{~h}, 3 \mathrm{~h}, 4 \mathrm{~h}$ as the cutoff values; ARR $(95 \% \mathrm{CI})$ of maternal adverse outcomes were 4.63(3.64,5.87), 7.80(5.85,10.41),
Table 2 Adverse delivery outcomes in multiparous women

\begin{tabular}{lll}
\hline & $\mathbf{n}$ & $\%$ \\
\hline Overall outcomes & 1677 & 23.6 \\
Maternal outcomes & 671 & 9.4 \\
Referral cesarean delivery & 98 & 1.4 \\
Instrumental delivery & 207 & 2.9 \\
Postpartum hemorrhage & 155 & 2.2 \\
III and IV degree laceration & 78 & 1.1 \\
Length of stay $\geq 90 t h$ & 332 & 4.7 \\
Neonatal outcomes & 1213 & 17.1 \\
NICU & 411 & 5.8 \\
Shoulder dystocia & 185 & 2.6 \\
Apgar $\leq 7$ (5 min) & 89 & 1.3 \\
Neonatal resuscitation & 790 & 11.1 \\
Assisted ventilation & 181 & 2.5 \\
\hline Overall outcomes include maternal and neonatal adverse outcomes &
\end{tabular}

14.11(9.59,20.78), 18.24(10.47,31.78); ARR (95\% CI) of neonatal adverse outcomes were 1.61(1.30,2.00), 1.75(1.30,2.35), $2.48(1.68,3.66), 1.48(0.81,2.73)$. Other adverse outcomes were showed in Additional file 4: Table S4, Fig. 5.

The total stage of labor was stratified to $<12 \mathrm{~h}, 12-23.9 \mathrm{~h}$, and $\geq 24 \mathrm{~h}$. With the increase of total stage of labor, the rate of overall adverse outcomes were $21.5,30.8,42.4 \%\left(X^{2}=\right.$ 84.90, $P<0.001)$; the rate of material adverse outcomes were $7.3,15.7,33.2 \%\left(X^{2}=195.48, P<0.001\right)$; the rate of neonatal adverse outcomes were 16.4, 20.0, 19.6\% $\left(X^{2}=8.61, P=\right.$ 0.003 ). The rate was (significantly) different in terms of referral cesarean delivery, instrumental delivery, postpartum hemorrhage, III and IV degree laceration, length of stay $\geq 90$ th, Apgar $\leq 7(5 \mathrm{~min})$, neonatal resuscitation, and assisted ventilation (Table 5, Fig. 6). With total stage of labor $<12 \mathrm{~h}$ as the reference, the risk of overall adverse outcomes, ARR (95\% CI) were 1.41(1.16,1.72), $3.17(2.10,4.80)$ in subgroups of $12-23.9 \mathrm{~h}, \geq 24 \mathrm{~h}$, the risk of maternal outcomes, ARR $(95 \% \mathrm{CI})$ was $2.40(1.84,3.12), 6.57(4.14,10.42)$, and the risk of neonatal outcomes, ARR $(95 \% \mathrm{CI})$ was $1.01(0.80,1.28)$, 1.41 (0.86,2.30), (Additional file 5: Table S5, Fig. 7). Regarding the impact of the total stage on the risk of overall adverse outcomes, ARR $(95 \% \mathrm{CI})$ were $1.59(1.32,1.91)$ with 12 $\mathrm{h}, 24 \mathrm{~h}$ as the cutoff values; ARR $(95 \% \mathrm{CI})$ of maternal adverse outcome was $2.84(2.23,3.62)$ with $12 \mathrm{~h}$ as the cutoff value, but there was no effect on the neonatal adverse outcomes (Additional file 6: Table S6, Fig. 7).

\section{Discussion}

There has been a constant debate on the duration of stage of labor. In decades, Friedman's Chart has been used to assist in the management of labor [2], and the duration of the stage of labor was defined based on it. Zhang and others proposed a new delivery curve [11], that was referred by the ACOG consensus in 2014. Then 
Table 3 Adverse outcomes in the first stage of labor in multiparous women ( $n=7109)$

\begin{tabular}{|c|c|c|c|c|c|c|c|}
\hline & \multicolumn{5}{|c|}{ Duration of First stage of labor } & \multirow{2}{*}{$\begin{array}{l}\text { Linear } \\
\text { trend } \\
X^{2}\end{array}$} & \multirow[t]{2}{*}{$P$} \\
\hline & $<6 \mathrm{~h}$ & $6-11.9 \mathrm{~h}$ & $12-17.9 \mathrm{~h}$ & $18-23.9 \mathrm{~h}$ & $\geq 24 \mathrm{~h}$ & & \\
\hline Overall outcomes & $714(21.0)$ & $588(23.4)$ & $236(28.8)$ & $81(35.5)$ & $58(38.4)$ & 57.64 & $<0.001$ \\
\hline Maternal outcomes & $246(7.2)$ & $221(8.8)$ & 113(13.8) & $46(20.2)$ & 45(29.8) & 121.38 & $<0.001$ \\
\hline Referral cesarean delivery & $28(0.8)$ & $29(1.2)$ & $20(2.4)$ & $13(5.7)$ & $8(5.3)$ & 50.97 & $<0.001$ \\
\hline Instrumental delivery & $77(2.3)$ & $72(2.9)$ & $35(4.3)$ & $12(5.3)$ & $11(7.3)$ & 23.46 & $<0.001$ \\
\hline Postpartum hemorrhage & $72(2.5)$ & $53(2.5)$ & $18(2.6)$ & $9(4.7)$ & $3(2.3)$ & 0.73 & 0.393 \\
\hline III and IV degree laceration & $34(1.1)$ & $23(1.0)$ & $14(1.9)$ & $4(2.0)$ & $3(2.3)$ & 3.76 & 0.053 \\
\hline Length of stay $\geq 90$ th & $100(2.9)$ & $100(4.0)$ & $67(8.2)$ & $31(13.6)$ & $34(22.5)$ & 160.81 & $<0.001$ \\
\hline Neonatal outcomes & $543(16.0)$ & 435(17.3) & 158(19.3) & $49(21.5)$ & $28(18.5)$ & 7.75 & 0.005 \\
\hline $\mathrm{NICU}$ & 184(5.4) & 150(6.0) & $54(6.6)$ & $16(7.0)$ & $7(4.6)$ & 1.14 & 0.285 \\
\hline Shoulder dystocia & $76(2.3)$ & $73(3.0)$ & $20(2.5)$ & $10(4.5)$ & $6(4.1)$ & 4.33 & 0.037 \\
\hline Apgar $\leq 7(5 \mathrm{~min})$ & $24(0.7)$ & $42(1.7)$ & $15(1.8)$ & $5(2.2)$ & $3(2.0)$ & 12.66 & $<0.001$ \\
\hline Neonatal resuscitation & $354(11.0)$ & $287(12.2)$ & $101(13.3)$ & $31(15.3)$ & $17(13.1)$ & 5.77 & 0.016 \\
\hline Assisted ventilation & $72(2.2)$ & $66(2.8)$ & $31(4.1)$ & $8(3.9)$ & $4(2.7)$ & 7.13 & 0.008 \\
\hline
\end{tabular}

Data was presented as $\mathrm{n}(\%)$. Linear trend Chi-square test for categorical data

Cohen and Friedman claimed that the new curve incorrectly explained the Friedman curve [12]. Studies after $2014[5,6]$ showed that prolonged stage of labor would not reduce the rate of cesarean section delivery, but would increase the adverse outcomes of delivery. Most of these studies tended to classify the stage of labor into normal and abnormal stage, with the intention of implementation of intervention. The stage of labor of multiparous women was different from that of nulliparous women. After the promulgation of the consensus in 2014, we wanted to figure out the impact of stage of labors of multiparous women on the adverse delivery outcomes. There was $5.3 \%$ of multiparous women of first stage $\geq 18 \mathrm{~h}, 3.7 \%$ of second stage $\geq 3 \mathrm{~h}$, and $2.6 \%$ of total stage $\geq 24 \mathrm{~h}$, these durations were not recommended neither by the ACOG consensus nor by Friedman's Chart. When the overall rate of cesarean delivery was $31.29 \%$, the rate of referral cesarean deliveries was $1.4 \%$, instrumental vaginal deliveries was $2.9 \%$ in this study.

The prolonged first stage of labor increased adverse maternal and neonatal outcomes in multiparous women in this study. With the prolongation of first stage, the rate of overall adverse outcomes increased from 21.0 to $38.4 \%$, both maternal and neonatal adverse outcomes showed an increasing trend. Compared with (the subgroup) $<6 \mathrm{~h}$ of first stage, the risks of long time stay in hospital, low Apgar score and admission to NICU increased in the subgroup of 6-11.9 h, the risks of assisted ventilation, referral cesarean delivery and instrumental delivery increased in the subgroup of $12-17.9 \mathrm{~h}$, the risks

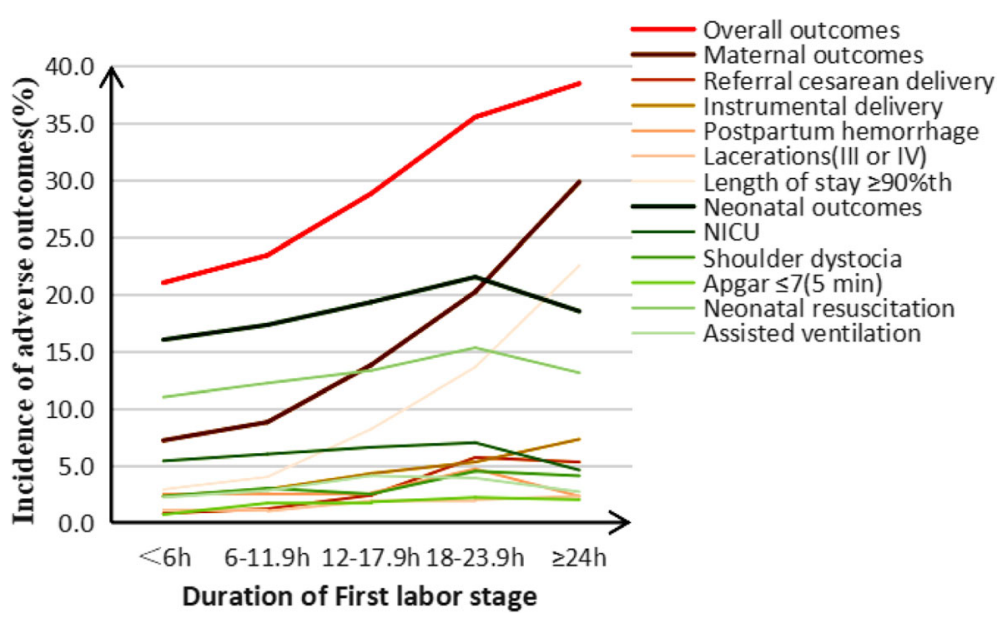

Fig. 2 Adverse outcomes in the first stage of labor in multiparous women 


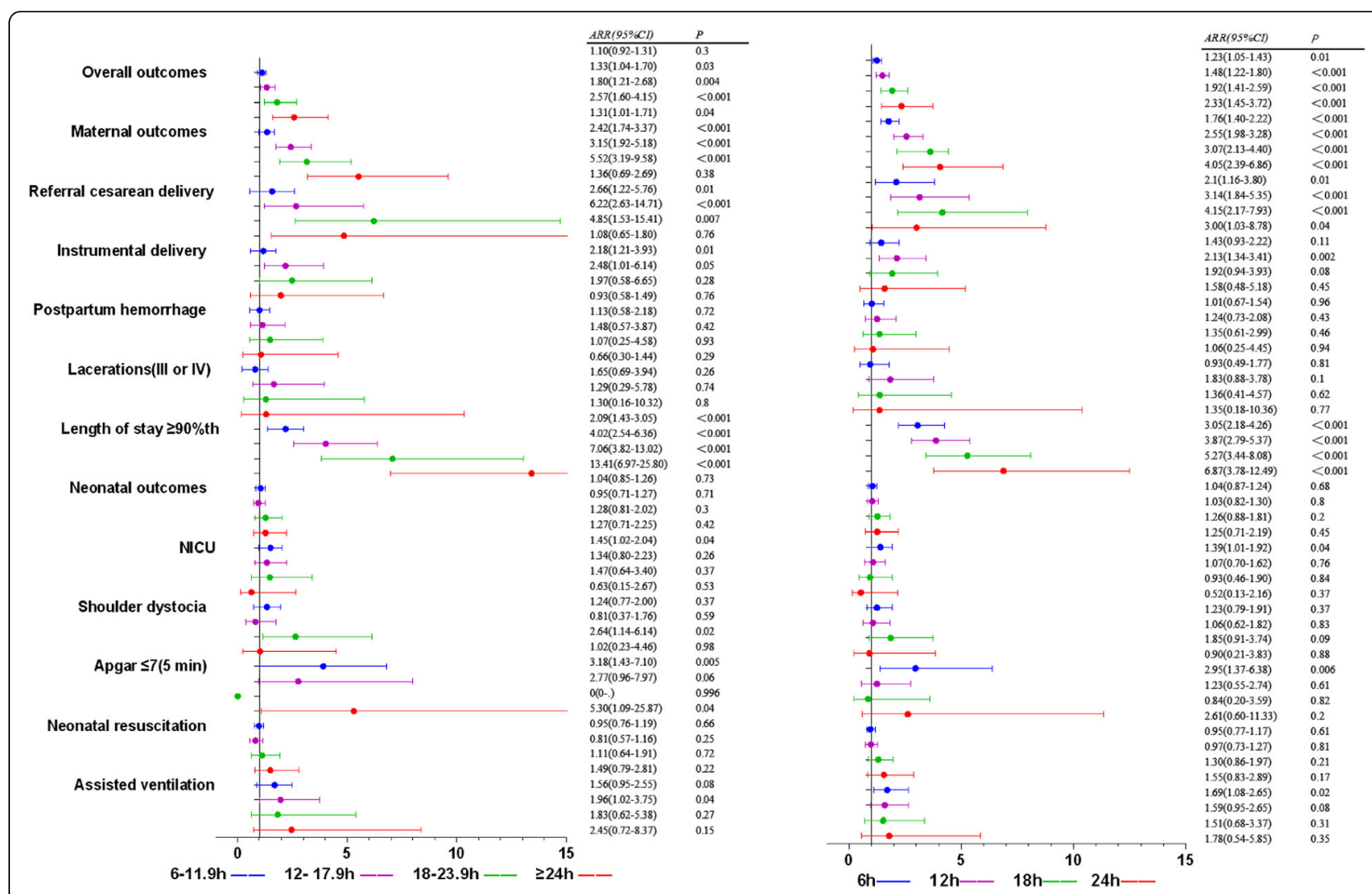

Fig. 3 Forest plots for multivariable logistic regression model of the first stage of labor. To assess the relationship between the duration of stage of labor and adverse delivery outcomes, the left was compared with $<1 \mathrm{~h}$, the right was compared with cutoff value. Adjusted gestational age, maternal age, maternal height, maternal BMI, gravidity, parity, baby weight, baby height, epidural, anesthesia, induction, oxytocin

Table 4 Adverse outcomes in the second stage of labor in multiparous women $(n=7109)$

\begin{tabular}{|c|c|c|c|c|c|c|c|}
\hline & \multicolumn{5}{|c|}{ Duration of second stage of labor } & \multirow{2}{*}{$\begin{array}{l}\text { Linear } \\
\text { trend } \\
X^{2}\end{array}$} & \multirow[t]{2}{*}{$P$} \\
\hline & $<1 \mathrm{~h}$ & $1-1.9 \mathrm{~h}$ & $2-2.9 \mathrm{~h}$ & $3-3.9 \mathrm{~h}$ & $\geq 4 \mathrm{~h}$ & & \\
\hline Overall outcomes & 1159(20.0) & 238(30.7) & 107(38.5) & $79(61.2)$ & $94(69.6)$ & 349.70 & $<0.001$ \\
\hline Maternal outcomes & $343(5.9)$ & 113(14.6) & $70(25.2)$ & $58(45.0)$ & $87(64.4)$ & 821.97 & $<0.001$ \\
\hline Referral cesarean delivery & $6(0.1)$ & $13(1.7)$ & $17(6.1)$ & 18(14.0) & $44(32.6)$ & 989.84 & $<0.001$ \\
\hline Instrumental delivery & $88(1.5)$ & $37(4.8)$ & $28(10.1)$ & 25(19.4) & $29(21.5)$ & 375.02 & $<0.001$ \\
\hline Postpartum hemorrhage & $90(1.8)$ & 25(3.8) & $6(2.7)$ & $12(10.4)$ & $22(19.0)$ & 130.31 & $<0.001$ \\
\hline III and IV degree laceration & $48(0.9)$ & $11(1.6)$ & $6(2.5)$ & $6(5.8)$ & $7(7.1)$ & 46.88 & $<0.001$ \\
\hline Length of stay $\geq 90$ th & $150(2.6)$ & $54(7.0)$ & $38(13.7)$ & $34(26.4)$ & $56(41.5)$ & 614.33 & $<0.001$ \\
\hline Neonatal outcomes & $924(16.0)$ & 152(19.6) & $59(21.2)$ & $41(31.8)$ & $37(27.4)$ & 38.06 & $<0.001$ \\
\hline $\mathrm{NICU}$ & 295(5.1) & $55(7.1)$ & $28(10.1)$ & $18(14.0)$ & 15(11.1) & 36.42 & $<0.001$ \\
\hline Shoulder dystocia & 150(2.6) & $22(2.9)$ & $7(2.6)$ & $4(3.3)$ & $2(1.5)$ & 0.05 & 0.83 \\
\hline Apgar $\leq 7(5 \mathrm{~min})$ & $48(0.8)$ & $17(2.2)$ & $6(2.2)$ & $13(10.1)$ & $5(3.7)$ & 64.22 & $<0.001$ \\
\hline Neonatal resuscitation & $609(11.2)$ & 95(13.1) & $30(11.9)$ & $30(25.2)$ & $26(21.1)$ & 24.22 & $<0.001$ \\
\hline Assisted ventilation & $123(2.3)$ & $23(3.2)$ & $10(4.0)$ & $14(11.8)$ & $11(8.9)$ & 48.11 & $<0.001$ \\
\hline
\end{tabular}




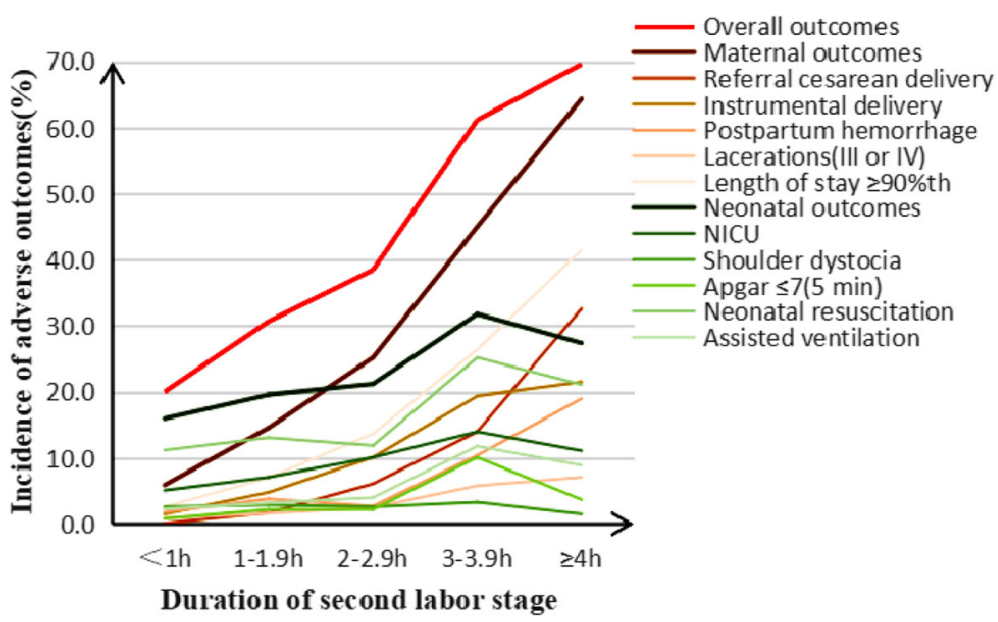

Fig. 4 Adverse outcomes in the second stage of labor in multiparous women

of long time stay in hospital and referral cesarean delivery increased in the subgroup $\geq 18 \mathrm{~h}$, even if confounder factors such as birth weight were adjusted. The risks of referral cesarean delivery, hospitalization stay $\geq 90$ th were 3.15 times and 4.27 times in subgroup $\geq 18 \mathrm{~h}$ of that in subgroup $<18 \mathrm{~h}$ of first stage. Therefore, we should comprehensively evaluate the possibility of vaginal delivery and the adverse outcomes, especially (when the duration of stage of labor is) $\geq 18 \mathrm{~h}$. Zhang and his colleagues pointed out that "our failure to reduce the

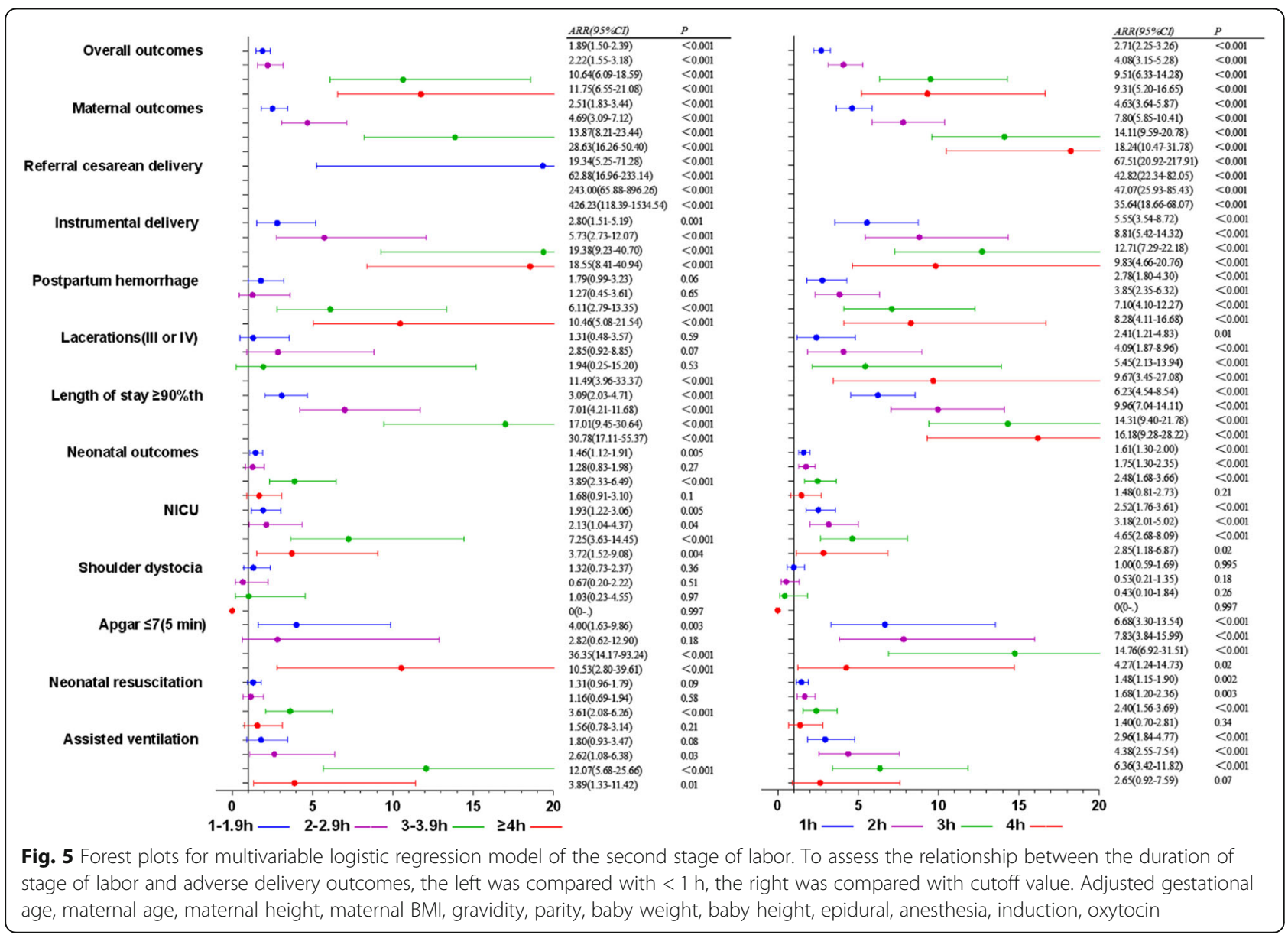


Table 5 Adverse outcomes in the total stage of labor in multiparous women. $(n=7109)$

\begin{tabular}{|c|c|c|c|c|c|}
\hline & \multicolumn{3}{|c|}{ Duration of total stage of labor } & \multirow{2}{*}{$\begin{array}{l}\text { Linear } \\
\text { trend } \\
X^{2}\end{array}$} & \multirow[t]{2}{*}{$P$} \\
\hline & $<12 \mathrm{~h}$ & $12-23.9 \mathrm{~h}$ & $\geq 24 \mathrm{~h}$ & & \\
\hline Overall outcomes & $1227(21.5)$ & $372(30.8)$ & $78(42.4)$ & 84.90 & $<0.001$ \\
\hline Maternal outcomes & $420(7.3)$ & 190(15.7) & $61(33.2)$ & 195.48 & $<0.001$ \\
\hline Referral cesarean delivery & $43(0.8)$ & 39(3.2) & $16(8.7)$ & 111.98 & $<0.001$ \\
\hline Instrumental delivery & $129(2.3)$ & $62(5.1)$ & $16(8.7)$ & 51.34 & $<0.001$ \\
\hline Postpartum hemorrhage & $113(2.3)$ & $34(3.3)$ & $8(5.1)$ & 6.86 & 0.009 \\
\hline III and IV degree laceration & $55(1.1)$ & $18(1.7)$ & $5(3.1)$ & 6.96 & 0.008 \\
\hline Length of stay $\geq 90$ th & 172(3.0) & 116(9.6) & $44(23.9)$ & 239.48 & $<0.001$ \\
\hline Neonatal outcomes & $936(16.4)$ & $241(20.0)$ & $36(19.6)$ & 8.61 & 0.003 \\
\hline $\mathrm{NICU}$ & $313(5.5)$ & $89(7.4)$ & $9(4.9)$ & 2.91 & 0.088 \\
\hline Shoulder dystocia & $143(2.5)$ & $35(3.0)$ & $7(3.9)$ & 1.68 & 0.194 \\
\hline Apgar $\leq 7(5 \mathrm{~min})$ & $58(1.0)$ & $27(2.2)$ & $4(2.2)$ & 11.83 & 0.001 \\
\hline Neonatal resuscitation & 615(11.4) & 154(13.9) & $21(13.1)$ & 4.62 & 0.032 \\
\hline Assisted ventilation & $131(2.4)$ & $44(4.0)$ & $6(3.8)$ & 7.70 & 0.006 \\
\hline
\end{tabular}

Data was presented as $\mathrm{n}(\%)$. Linear trend Chi-square test for categorical data

rate of cesarean section may be due to our failure to fully understand the delivery process, especially the first stage of labor" [13]. We should take a dynamic view on the first stage, define an abnormal first stage based on maternal and neonatal outcomes [7, 14], and pay attention to complications even at the beginning of labor.

The second stage was the most important stage of labor. The effect of the duration of the second stage of labor on the outcomes of labor has been studied widely and deeply, but the results were not consistent. Grantz's study showed the rate of spontaneous vaginal birth without morbidity decreased with prolonged duration of second stage [15]. Cheng YW and Laughon SK proposed that the benefits of the prolonged second stage of labor to promote the rate of vaginal delivery should be weighed against the increased adverse outcomes of mothers and infants [16, 17]. A randomized controlled study in 2016 showed that the prolonged second stage of labor could promote the rate of vaginal delivery and reduce the rate of cesarean section, but the impact of the prolonged second stage of labor on the adverse outcomes of mothers and infants was not statistically significant [18]. Thuillier $C$ and Zipori $Y$ reported the new consensus recommendations was associated with the reduction of the rate of primary cesarean delivery $[6$, 19]. Ausbeck EB's research showed prolonged second stage was associated with adverse maternal outcomes significantly, but not with adverse neonatal outcomes [20].

In this study, the rate of overall adverse outcomes increased rapidly from $20 \%$ in subgroup $\leq 1 \mathrm{~h}, 30.7 \%$ in $1-$ $1.9 \mathrm{~h}, 38.5 \%$ in $2-2.9 \mathrm{~h}$, to $61.2 \%$ in $3-3.9 \mathrm{~h}, 69.6 \%$ in $\geq 4$

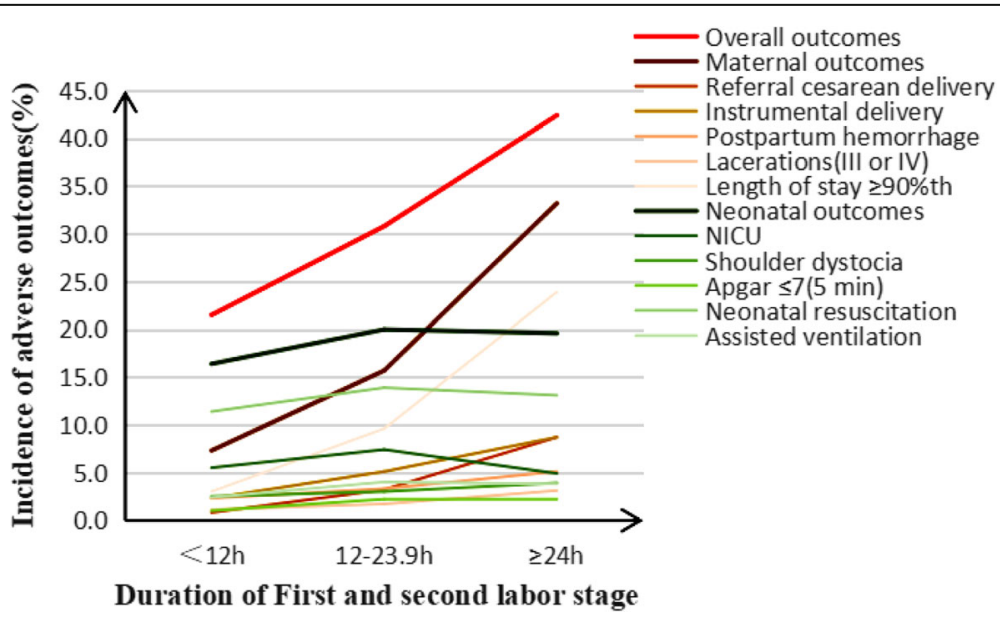

Fig. 6 Adverse outcomes in the total stage of labor in multiparous women 


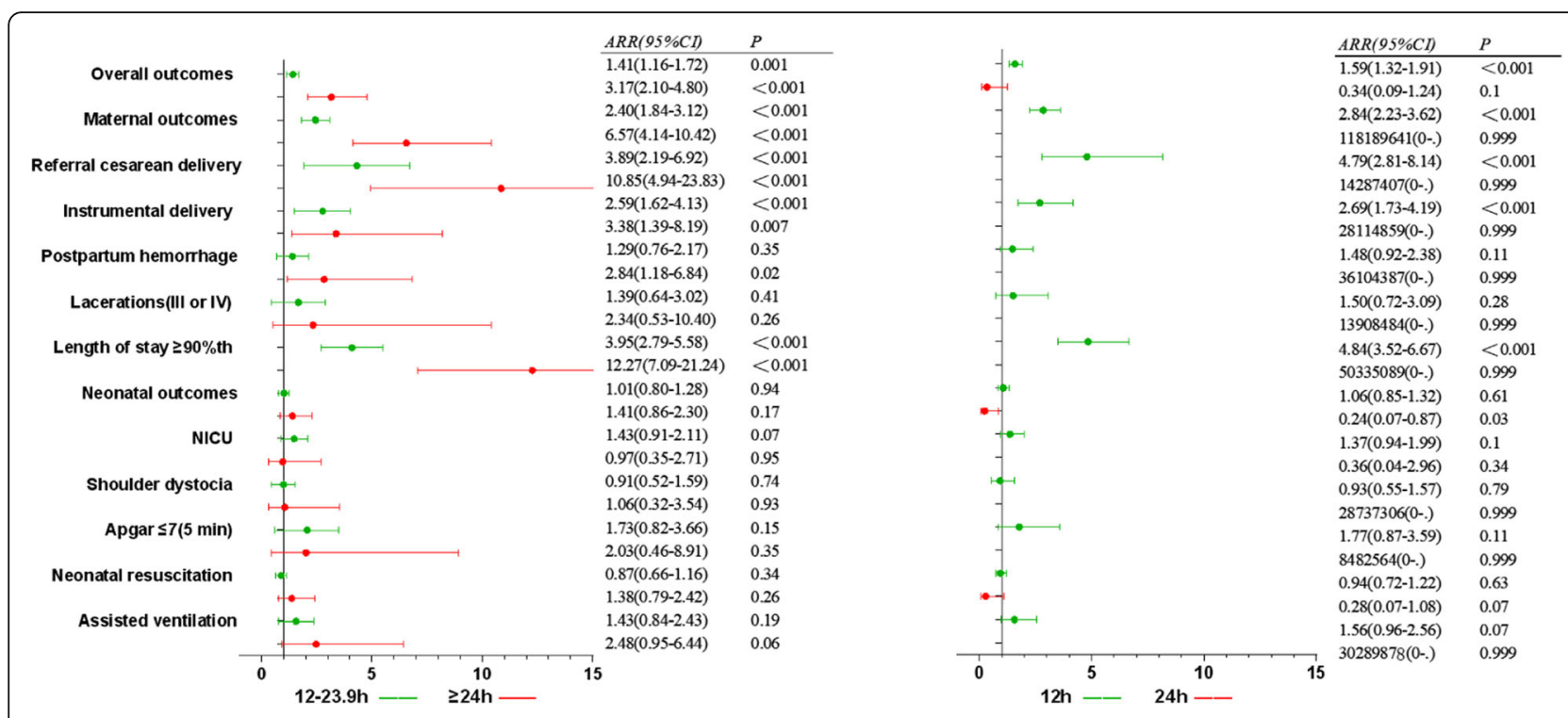

Fig. 7 Forest plots for multivariable logistic regression model of the total stage of labor. To assess the relationship between the duration of stage of labor and adverse delivery outcomes, the left was compared with $<12 \mathrm{~h}$, the right was compared with cutoff value. Adjusted gestational age, maternal age, maternal height, maternal BMl, gravidity, parity, baby weight, baby height, epidural, anesthesia, induction, oxytocin

h of second stage of labor. Except for shoulder dystocia, almost all adverse outcomes showed an increasing trend. Although the risk of shoulder dystocia increased with birth weight, and was related to prolonged stage of labor [21-23], but in this study, the shoulder dystocia reduced when the duration of second stage $\geq 4 \mathrm{~h}$, it might be owing to the increase of referral cesarean delivery with prolonged second stage and decrease of vaginal deliveries. The risk of maternal adverse outcomes increased for every additional hour, in referral cesarean delivery, instrumental delivery, postpartum hemorrhage, lacerations, hospitalization stay $\geq 90$ th. It also should be noticed that the prolonged second stage was an independent risk factor for adverse neonatal outcomes, in low Apgar score at $5 \mathrm{~min}$, neonatal resuscitation, assisted ventilation and admission to NICU, even though that was not significant in the first stage of labor.

The duration of second stage did not account much in the total stage, but more attention should be pay to it. Some harmless measures should be taken to make it shorter, such as upright position or immediate pushing $[24,25]$. It was important to assess the fetal position in second stage, occiput posterior position and transverse position were associated with more pain and prolonged stage of labor. Free position or manual rotation of fetal occiput in setting of fetal malposition in second stage of labor were reasonable interventions before instrumentassisted delivery or cesarean delivery [1, 26, 27].

Few studies have paid attention to total stage of labor. In this study, the rate of overall adverse outcomes was $21.5,30.8,42.4 \%$, in subgroups $<12 \mathrm{~h}, 12-17.9 \mathrm{~h}, \geq 18 \mathrm{~h}$. The risk of postpartum hemorrhage with the duration of total $\geq 24$ h was 1.84 times of that with the duration $<12$ h. There were correlation between the first and second stages of labor, the duration of the second stage significantly increased accordingly with the increase of duration of the first stage [28]. In the first stage, the risk factors should be identified and treated, such as uterine atony, fatigue, insufficient energy intake, supine position and so on. With the duration of first stage $\geq 18 \mathrm{~h}$, we should comprehensively weigh the possibility of vaginal delivery against the incidence of adverse outcomes. Especially with cephalopelvic disproportion or fetal distress, it should be referred to cesarean section in time. When the first stage was prolonged, we must be alert to the prolongation of the second stage, and pay more attention to the prevention of postpartum complications in parturients.

The strength of the study was that the adverse maternal and neonatal outcomes increased with prolongation of the first, second and total stage of labor, the longer the duration of stage, the higher the risk of adverse outcomes in multiparous women. The limitation of the study was that the data was collected retrospectively; the first stage of labor could not be classified into latent phase and active phase. The time points could not be defined very clearly from the first stage to the second sage, because the examination of dilated cervix was subjective. There was not a stratified analysis on epidural analgesia, induction and oxytocin.

\section{Conclusion}

The prolonged stage of labor may lead to increased adverse outcomes in multiparous women, no matter the first stage, the second stage or the total stage of labor, and it was an independent risk factor for adverse maternal and neonatal outcomes, increasing synchronously. 
The impact of prolonged stage of labor on maternal outcomes was more significant, and the prolonged second stage had an impact on neonatal outcomes. We suggest to pay attention to the stage of labor at the beginning, monitor the status of mothers and neonates, and take active measures to make stage of labor shorter and thus to reduce adverse delivery outcomes.

\section{Supplementary information}

Supplementary information accompanies this paper at https://doi.org/10. 1186/s12884-020-03286-z.

Additional file 1: Table S1 Risks of adverse outcomes in the first stage of labor in multiparous women. Multivariable logistic regression model was used to assess the relationship between the stage of labor and adverse delivery outcomes, $<6 \mathrm{~h}$ as a reference; Adjusted gestational age, maternal age, maternal height, maternal BMl, gravidity, parity, baby weight, baby height, epidural, anesthesia, induction, oxytocin.

Additional file 2: Table S2 Risks of adverse outcomes in different cutoff value of the first stage of labor in multiparous women.

Multivariable logistic regression model was used to assess risks of cutoff value of the stage of labor for adverse delivery outcomes. Adjusted gestational age, maternal age, maternal height, maternal BMI, gravidity, parity, baby weight, baby height, epidural, anesthesia, induction, oxytocin.

Additional file 3: Table S3 Risks of adverse outcomes in the second stage of labor in multiparous women. Multivariable logistic regression model was used to assess the relationship between the stage of labor and adverse delivery outcomes, $<1 \mathrm{~h}$ as a reference; Adjusted gestational age, maternal age, maternal height, maternal BMI, gravidity, parity, baby weight, baby height, epidural, anesthesia, induction, oxytocin.

Additional file 4: Table S4 Risks of adverse outcomes in different cutoff value of the second labor stage in multiparous women. Multivariable logistic regression model was used to assess risks of cutoff value of the stage of labor for adverse delivery outcomes. Adjusted gestational age, maternal age, maternal height, maternal BMI, gravidity, parity, baby weight, baby height, epidural, anesthesia, induction, oxytocin.

Additional file 5: Table S5 Risks of adverse outcomes in the total stage of labor in multiparous women. Multivariable logistic regression model was used to assess the relationship between the stage of labor and adverse delivery outcomes, $<12 \mathrm{~h}$ as a reference; Adjusted gestational age, maternal age, maternal height, maternal BMI, gravidity, parity, baby weight, baby height, epidural, anesthesia, induction, oxytocin.

Additional file 6: Table S6 Risks of adverse outcomes in different cutoff value of the total stage of labor in multiparous women. Multivariable logistic regression model was used to assess risks of cutoff value of the stage of labor for adverse delivery outcomes. Adjusted gestational age, maternal age, maternal height, maternal BMl, gravidity, parity, baby weight, baby height, epidural, anesthesia, induction, oxytocin.

\section{Abbreviations}

ARR: Adjusted Risk Ratio; Cl: Confidence Interval; ACOG: American College of Obstetricians and Gynecologists

\section{Acknowledgements}

Not applicable.

\section{Authors' contributions}

WL designed the study and wrote the initial manuscript. QW and LF collected the data. WH and $J \mathrm{~L}$ analyzed the data. ZJ oversaw the process and gave critical comments to the study design, interpretation and revised the draft. All authors read and approved the final manuscript.

\section{Funding}

No funding.

\section{Availability of data and materials}

The datasets used in the current study are available from the corresponding author on reasonable request.

\section{Ethics approval and consent to participate}

This study was approved by Harvard University Partners Healthcare Systems, the ethical approval number was 2018P002646.

\section{Consent for publication}

It is not applicable.

\section{Competing interests}

All authors declare that they have no competing interests.

\section{Author details}

${ }^{1}$ Department of Obstetrics and Gynecology, Hebei General Hospital, Hebei Medical University, Shijiazhuang 050051, China. ${ }^{2}$ Department of Anesthesiology, Perioperative and Pain Medicine, Brigham and Women's Hospital, Harvard Medical School, 75 Francis St, Boston, MA 02115, USA. ${ }^{3}$ Department of Obstetrics and Gynecology, Hebei General Hospital, North China University of Science and Technology, Shijiazhuang 050051, China. ${ }^{4}$ Department of Obstetrics, Chengdu Women's and Children's Central Hospital, Chengdu 610073, China. ${ }^{5}$ Department of Otolaryngology-Head and Neck Surgery, Chongqing general hospital, University of Chinese Academy of Science, Chongqing 40001, China.

Received: 10 April 2020 Accepted: 25 September 2020

Published online: 07 October 2020

\section{References}

1. American College of $\mathrm{O}$, Gynecologists, Society for Maternal-Fetal M, Caughey AB, Cahill AG, Guise JM, Rouse DJ. Safe prevention of the primary cesarean delivery. Am J Obstet Gynecol. 2014;210(3):179-93.

2. Friedman E. The graphic analysis of labor. Am J Obstet Gynecol. 1954;68(6): 1568-75.

3. Nelson DB, McIntire DD, Leveno KJ. Second-stage labor: consensus versus science. Am J Obstet Gynecol. 2019;222(2):144-9.

4. Leveno KJ, Nelson DB, Mclntire DD. Second-stage labor: how long is too long? Am J Obstet Gynecol. 2016;214(4):484-9.

5. Rosenbloom Jl, Stout MJ, Tuuli MG, Woolfolk CL, Lopez JD, Macones GA Cahill AG. New labor management guidelines and changes in cesarean delivery patterns. Am J Obstet Gynecol. 2017;217(6):689 e681-8.

6. Zipori Y, Grunwald O, Ginsberg Y, Beloosesky R, Weiner Z. The impact of extending the second stage of labor to prevent primary cesarean delivery on maternal and neonatal outcomes. Am J Obstet Gynecol. 2019;220(2):191. e191-7.

7. Harper LM, Caughey AB, Roehl KA, Odibo AO, Cahill AG. Defining an abnormal first stage of labor based on maternal and neonatal outcomes. Am J Obstet Gynecol. 2014;210(6):536 e531-7.

8. Rhoades JS, Cahill AG. Defining and managing Normal and abnormal first stage of labor. Obstet Gynecol Clin N Am. 2017:44(4):535-45.

9. Stephansson O, Sandstrom A, Petersson G, Wikstrom AK, Cnattingius S. Prolonged second stage of labour, maternal infectious disease, urinary retention and other complications in the early postpartum period. BJOG. 2016;123(4):608-16

10. Ashwal E, Livne MY, Benichou JIC, Unger R, Hiersch L, Aviram A, Mani A, Yogev Y. Contemporary patterns of labor in nulliparous and multiparous women. Am J Obstet Gynecol. 2020;222(3):267.e1-9.

11. Zhang J, Troendle J, Grantz KL, Reddy UM. Statistical aspects of modeling the labor curve. Am J Obstet Gynecol. 2015;212(6):750.e751-4.

12. Cohen WR, Friedman EA. Misguided guidelines for managing labor. Am J Obstet Gynecol. 2015;212(6):753.e751-3.

13. Zhang J, Troendle J, Mikolajczyk R, Sundaram R, Beaver J, Fraser W. The natural history of the normal first stage of labor. Obstet Gynecol. 2010; 115(4):705-10.

14. Cheng YW, Shaffer BL, Bryant AS, Caughey AB. Length of the first stage of labor and associated perinatal outcomes in nulliparous women. Obstet Gynecol. 2010;116(5):1127-35.

15. Grantz KL, Sundaram R, Ma L, Hinkle S, Berghella V, Hoffman MK, Reddy UM. Reassessing the duration of the second stage of labor in relation to maternal and neonatal morbidity. Obstet Gynecol. 2018;131(2):345-53. 
16. Cheng YW, Hopkins LM, Laros RK Jr, Caughey AB. Duration of the second stage of labor in multiparous women: maternal and neonatal outcomes. Am J Obstet Gynecol. 2007;196(6):585 e581-6.

17. Laughon SK, Berghella V, Reddy UM, Sundaram R, Lu Z, Hoffman MK. Neonatal and maternal outcomes with prolonged second stage of labor. Obstet Gynecol. 2014;124(1):57-67.

18. Gimovsky AC, Berghella V. Randomized controlled trial of prolonged second stage: extending the time limit vs usual guidelines. Am J Obstet Gynecol. 2016;214(3):361 e361-6.

19. Thuillier C, Roy S, Peyronnet V, Quibel T, Nlandu A, Rozenberg P. Impact of recommended changes in labor management for prevention of the primary cesarean delivery. Am J Obstet Gynecol. 2018;218(3):341 e341-9.

20. Ausbeck EB, Jennings SF, Champion M, Gray M, Blanchard C, Tita AT, Harper LM. Perinatal outcomes with longer second stage of labor: a risk analysis comparing expectant management to operative intervention. Am J Perinatol. 2020;24. https:/doi.org/10.1055/s-0040-1708799.

21. Revicky V, Mukhopadhyay S, Morris EP, Nieto JJ. Can we predict shoulder dystocia? Arch Gynecol Obstet. 2012;285(2):291-5.

22. Temerinac $D$, Chen $X$, Sütterlin $M$, Kehl $S$. Influence of fetal birth weight on perinatal outcome in planned vaginal births. Arch Gynecol Obstet. 2013; 289(2):313-8.

23. Palatnik A, Grobman WA, Hellendag MG, Janetos TM, Gossett DR, Miller ES. Predictors of shoulder dystocia at the time of operative vaginal delivery. Am J Obstet Gynecol. 2016;215(5):624 e621-5.

24. Cahill AG, Srinivas SK, Tita ATN, Caughey AB, Richter HE, Gregory WT, Liu J, Woolfolk C. Weinstein DL, Mathur AM, et al. Effect of immediate vs delayed pushing on rates of spontaneous vaginal delivery among nulliparous women receiving Neuraxial analgesia: a randomized clinical trial. Jama. 2018:320(14):1444-54.

25. Epidural, Position Trial Collaborative G. Upright versus lying down position in second stage of labour in nulliparous women with low dose epidural: BUMPES randomised controlled trial. Bmj. 2017;359:j4471.

26. Bueno-Lopez V, Fuentelsaz-Gallego C, Casellas-Caro M, Falgueras-Serrano AM, Crespo-Berros S, Silvano-Cocinero AM, Alcaine-Guisado C, Zamoro Fuentes M, Carreras E, Terre-Rull C. Efficiency of the modified Sims maternal position in the rotation of persistent occiput posterior position during labor: a randomized clinical trial. Birth. 2018;45(4):385-92.

27. O'Brien S, Jordan S, Siassakos D. The role of manual rotation in avoiding and managing OVD. Best Pract Res Clin Obstet Gynaecol. 2019;56:69-80.

28. Nelson DB, McIntire DD, Leveno KJ. Relationship of the length of the first stage of labor to the length of the second stage. Obstet Gynecol. 2013; 122(1):27-32.

\section{Publisher's Note}

Springer Nature remains neutral with regard to jurisdictional claims in published maps and institutional affiliations.

Ready to submit your research? Choose BMC and benefit from:

- fast, convenient online submission

- thorough peer review by experienced researchers in your field

- rapid publication on acceptance

- support for research data, including large and complex data types

- gold Open Access which fosters wider collaboration and increased citations

- maximum visibility for your research: over $100 \mathrm{M}$ website views per year

At $\mathrm{BMC}$, research is always in progress.

Learn more biomedcentral.com/submissions 